\title{
Development of an intervention plan for Charleston and Karamay
}

\author{
Yue Huan \\ School of North China Electric Power University(Baoding), Baoding 071000, China \\ 896779907@qq.com
}

Keywords: Intervention plan, The gray prediction model, Sensitivity analysis

\begin{abstract}
Charleston County and Karamay. Then use the gray prediction model to predict the change of the six indicators in few decades, and then obtain the urban development level before the planned intervention. Assumptions necessary are set to analysis indicators change. By comparing urban development level before and after intervention, we find our plan plays a good role. The equity situation in Charleston is resolved, while the environmental of Karamay is improved too. Subsequently perform sensitivity analysis to indicate the importance of its selection for each country.
\end{abstract}

\section{Introduction}

In order to determine whether the growth plan of Charleston county and Karamay is successful, we qualitatively analyze the growth plans for the two cities which are found on their government websites, and find that the plans do not cover all the principles. We obtain the relevant data from 2007 to 2014, and calculate the level of urban development according to the weight of indicators. To sum up, we believe that the smart growth plan of Charleston county is successful, but it still needs to make efforts in unemployment and health insurance. As for Karamay, we can know that its urban development level is rapidly growing, which is majorly affected by the improvement of the income per capita and crime rate. At the same time, we also need to pay attention to, the air quality and urban development level. The air quality in Karamay is disappointing. And the urban development level at a relatively low level (less than 70). So we think Karamay needs to adjust its growth plan.

\section{Our growth plan for the two cities}

Based on our analysis, a growth plan is put forward for two cities. In the process, we consider emphatically the influential drivers which have options to improve. Subsequently, we predict the value of 6 indicators (Cost of living index, Income per capita, Air quality index, Unemployment rate, Percentage of population without health insurance coverage(PPWHIC), and Urban development index), then calculate the value of urban development level to judge the success of smart growth.

\subsection{Plan statement}

1) Create a unique industrial chain. Rational development and utilization of local resources to form a local economic advantage. For example, vigorously develop the tourism industry through the development of local cultural resources and the conduction of cultural activities; according to the local mineral resources, construct the characteristic industrial chain.

2) Improve the health care laws and relevant agencies. Develop a comprehensive care model, which integrates primary care, acute care, long-term service and other service models together to provide high-quality care for the elderly and the disabled. In addition, it is necessary to improve the professional skills of staff. Effective management of health care database information is also needed, to improve the accessibility and usability of related websites.

3) Encourage enterprises to increase employment to create more job opportunities. Strengthen employment training to improve the quality of labor force. Besides, make full use of the advantages of local universities in cultivating talents of education, and carry out multi-level employment and reemployment training, to provide well-trained workers. The establishment of early warning mechanism to help us take preventive measures. 
4) Reduce pollutant emissions, and absorb existing air pollutants. Exhaust emissions after reaching the standard of purification through science and technology, or use clean energy, such as solar and wind. On the other hand, increase vegetation coverage to use photosynthesis of green plants to absorb pollutants; at the same time, it is essential to improve people's awareness of environmental protection. Moreover, check the air quality regularly, and deal with problems in time. [1][2]

5) Improve the social security system, and reduce the possibility of crime. Develop relevant laws and regulations, and improve the efficiency of criminal procedure. Avoid repressive policies, to prevent the emergence of "iron fist" strategy in the central United States; strengthen gun control and reduce gun crime by cutting off the supply of illegal firearms; in addition, implement legal education and carry out legal activities. [3]

In conclusion, our plan can improve the indicators situation in both cities. But implementing our plan, may cause large expenditure, or need a long time to work, which results in some obstacles to the plan.

\subsection{Evaluate the success of our growth plan}

Now, we want to test the performance of our plan stated above. Because we consider some items of the plan have comprehensive and unmeasurable impacts on the evaluating indicators, some assumptions are made to simplify our model.

\subsubsection{Assumptions}

1. Since the cost of living index is inconvenient to calculate, we use five years' average index from 2009 to 2013 instead. We make this assumption to simplify the calculation, although there may be some influence.

2. The Charleston County's air quality is already in a good state, so we think it will become to 40 which hardly changes compare with the previous. As for Karamay, according to the air quality of surrounding cities, we predict that it will reduce the air quality index to 125 after the implementation.

3. In terms of population rate, we think $\mathrm{R} \approx 0.4 \%$ in Charleston and $\mathrm{R} \approx 3.34 \%$ in karamay is a very good estimate in few decades after studying many literature. [4]

4. The proportion of labor force in population e in the studied cities is constant over few decades. The proportion of Charleston is 0.62 , while Karamay's proportion is 0.73 .

2.2.2 Analysis of the indicators

Due to the complexity of the four indicators predicted, we decide to forecast related intermediate variables using Gray Forecasting Model (GFM) to obtain the predicted values of the three indexes .After that, compare the difference of the results to measure our growth plan.

In terms of unemployment rate, we first compute the annual employment opportunities of the region in 2007-2013 and predict the employment opportunities after 2013. The equation is:

\section{$E O_{i}=T L_{i} \times\left(1-U R_{i}\right)$}

Where $\mathrm{EO}_{\mathrm{i}}$ denotes employment opportunities in $\mathrm{i}^{\text {th }}$ year, $\mathrm{TL}_{\mathrm{i}}$ denotes total labor force in $\mathrm{i}^{\text {th }}$ year and $\mathrm{UR}_{\mathrm{i}}$ denotes unemployment rate in $\mathrm{i}^{\text {th }}$ year.

We calculate the number of people who are eligible for Medicare in the region to forecast the number of people who are eligible for Medicare in $\mathrm{i}^{\text {th }}$ years. The formula is as follows:

$$
N M P_{i}=T P_{i} \times\left(1-U R_{i}\right)
$$

As for income per capita, we predict the total regional GDP.

In addition, crime index is also forecasted by GFM.

\section{Application of Gray Forecasting Model}

If a set of time series data has obvious trend, Grey Forecasting Model in the Grey System Theory can give a precise prediction even with few data (more than 4$)$. We apply GM $(1,1)$ model, the most widely used Grey Forecasting Model, to forecast the value of 4 indicators, i.e. Crime index, the employment opportunities, the total regional GDP and the number of people who are eligible for Medicare. Our data comes from world statistics websites. For each indicator, we use the data from 2007 to 2013, which is sufficient for GM(1,1) model.[5]

Then we calculate the four indicators by the for forecasted values using the following equations: 


$$
\begin{gathered}
\mathrm{UR}=\frac{P_{o}(1+R)^{n} e-E O}{P_{o}(1+R) e} \\
\mathrm{PPWHIC}=\frac{P_{o}(1+R)^{n} e-N M P}{P_{o}(1+R)^{n}} \\
\mathrm{IPC}=\frac{R G E P}{P_{o}(1+R)^{n}}
\end{gathered}
$$

Where $\mathrm{P}_{\mathrm{o}}$ denotes the population in 2013, and e denotes the proportion of the labor force in the population.

In the calculation process, we find that the economic crisis in 2009, has a great impact on the indicators. Consequently, we remove the outliers.

Run our model by the matlab software, we obtain the results. Table 1 below shows the changes of

\begin{tabular}{|c|c|c|c|c|}
\hline & \multicolumn{2}{|c|}{ Values of current plan } & \multicolumn{2}{|c|}{ Values of our plan } \\
\hline indicators & 2018 & 2023 & 2018 & 2023 \\
\hline Cost of living index & 93.74 & 93.74 & 93.74 & 93.74 \\
\hline Income per capita Air & 43646 & 43956 & 43922 & 44805 \\
\hline quality index & 40 & 40 & 40 & 40 \\
\hline Unemployment rate & $5 \%$ & $4.34 \%$ & $4.3 \%$ & $3.3 \%$ \\
\hline Crime index & 86.6 & 72.5 & 70 & 50 \\
\hline $\begin{array}{l}\text { Percentage of population without health } \\
\text { insurance coverage }\end{array}$ & $20 \%$ & $21 \%$ & $16 \%$ & $14 \%$ \\
\hline 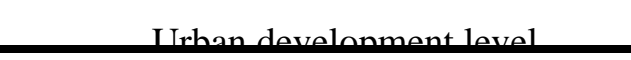 & 81.59 & 83.13 & 83.49 & 86.14 \\
\hline \multicolumn{5}{|c|}{ Table 2 The result of prediction values in Karamay City } \\
\hline & \multicolumn{2}{|c|}{ Values of current plan } & \multicolumn{2}{|c|}{ Values of our plan } \\
\hline indicators & 2018 & 2023 & 2018 & 2023 \\
\hline Cost of living index & 83.02 & 83.02 & 83.02 & 83.02 \\
\hline Income per capita Air & 38453 & 39784 & 39570 & 40214 \\
\hline quality index & 182 & 182 & 125 & 125 \\
\hline Unemployment rate & $2 \%$ & $1.7 \%$ & $1.8 \%$ & $1.5 \%$ \\
\hline Crime index & 230 & 200 & 215 & 190 \\
\hline $\begin{array}{l}\text { Percentage of population without health } \\
\text { insurance coverage }\end{array}$ & $10 \%$ & $8 \%$ & $8 \%$ & $7 \%$ \\
\hline Urban development level & 67.5 & 71.3 & 70.5 & 7 \\
\hline
\end{tabular}
all indicators in Charleston in 2013 and 2018. The results of Karamay are presented in the table 2.

Table 1 The result of prediction values in Charleston County

(PPHWC denotes Percentage of population without health insurance coverage, IPC denotes income per capita.) 
Analyzing the results above, we get the conclusion that improvement happens in some indicators, resulting in increase of urban development level by carrying out our plan. Therefore, our growth plan is successful for both cities.

\section{Conclusions}

Because the level of urban development is affected by the average annual growth rate of the population, we take Charleston County as an example to observe changes in urban development levels $(\mathrm{R} \in[0.001,0.02])$ at different annual average growth rate:

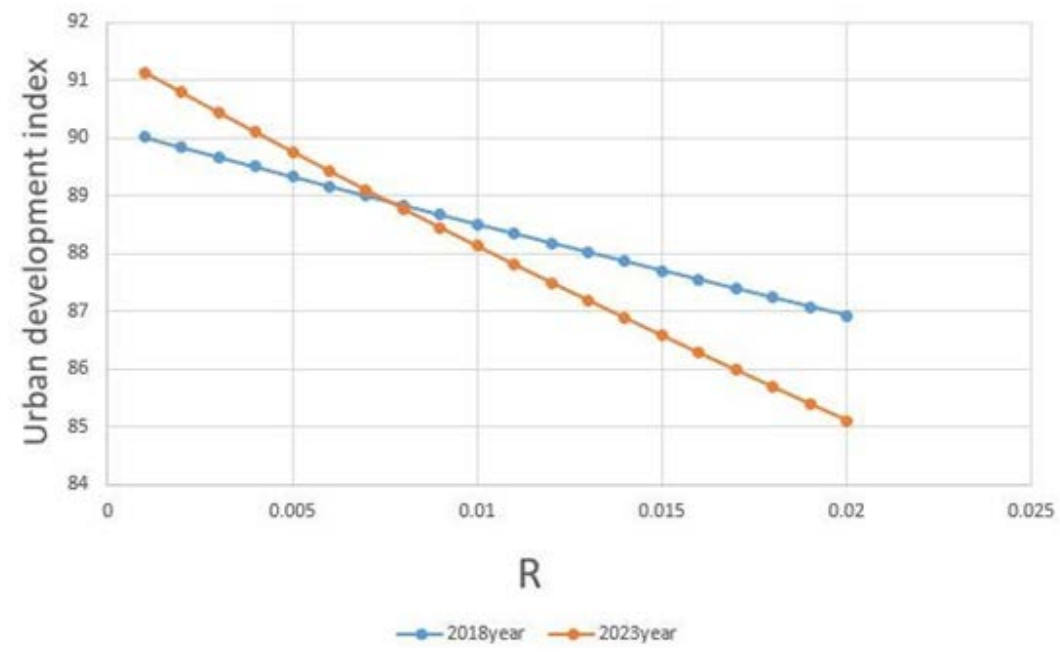

We can see that different $\mathrm{R}$ values will have different effects on the level of urban development. Under the same condition, the higher the $\mathrm{R}$ value is, the lower the urban development level is. And when the $\mathrm{R}$ value is greater than 0.008, the level of urban development in 2023 will be less than the level of urban development in 2018, which means that too much population will cause the city to bear the pressure.

\section{References}

[1]. Seattle OPCD - Economic Development Element, Mayor's Recommended Plan May 2016, http://www.seattle.gov/dpd/cs/groups/pan/@pan/documents/web-informational/p 2450584.pdf

[2]. Strategic Goal 1 | HHS.gov, https://www.hhs.gov/about/strategic-plan/strategic-goal-1/\#obj-a

[3]. Five.Ways.to.Reduce.Crime.Urban.Institute,http://www.urban.org/urban-wire/five-ways-reduce -crime

[4]. Charleston County population,

[5]. http://population.us/county/sc/charleston-county/

[6]. Julong D. Introduction to grey system theory[J]. The Journal of grey system, 1989, 1(1): 1-24. 